\title{
Universidad y diversidad cultural. Diálogos imperfectos ${ }^{1}$
}

\author{
María Fernanda Martínez Hoyos ${ }^{2}$, Diana Milena Rodríguez Pabón ${ }^{3}$ \\ CONSIDERACIÓN ${ }^{4}$
}

\begin{abstract}
Resumen
El presente artículo se deriva de la investigación denominada Universidad y Diversidad Cultural. Diálogos imperfectos ${ }^{5}$, en la que nos preguntamos sobre los sentidos de diversidad cultural que se están construyendo/movilizando en los estudiantes de noveno semestre y docentes del programa de Licenciatura en Matemáticas de la Universidad de Nariño. Para dar respuesta a la pregunta de investigación, se desarrolló una metodología basada en el enfoque Hermenéutico-colectivo que propone develar los sentidos y significados de los sujetos a través del diálogo de saberes; las técnicas utilizadas para la recolección de la información fueron: el análisis documental, la entrevista a profundidad con informantes clave y los grupos de discusión; los instrumentos diseñados se sometieron a una validación interjueces y una prueba piloto y el análisis de información se realizó por medio de la categorización inductiva derivada del proceso de triangulación de la información que se realizó entre las fuentes y técnicas utilizadas. Los principales hallazgos de la investigación muestran que los sentidos de diversidad cultural que se están movilizando en estudiantes y docentes giran en torno a los siguientes aspectos: un énfasis étnico racial de la diversidad cultural, la diversidad vista como déficit o limitación, una postura multicultural dirigida al respeto por la diferencia, una contradicción entre la posición institucional y las demandas del sistema educativo nacional y un cuestionamiento frente al verdadero sentido que adquiere la diversidad cultural en los procesos educativos y que puede convertirlos en nuevos sistemas de imposición y dominio.
\end{abstract}

Palabras clave: Diversidad, diversidad cultural, educación, multiculturalidad, interculturalidad.

1 Recibido: 10 de septimbre de 2012. Aceptado: 19 de octubre de 2012.

2 María Fernanda Martínez Hoyos. Orientadora Escolar en la Institución Educativa Heraldo Romero Sánchez de Pasto Nariño. Psicóloga de la Universidad de Nariño. Magister en Educación desde la diversidad. Correo electrónico: mariafermatinez13@gmail.com

3 Diana Milena Rodríguez Pabón. Coordinadora Área de Promoción Socioeconómica del Sistema de Bienestar Universitario de la Universidad de Nariño Municipio de Pasto. Psicóloga Universidad de Nariño. Magister en Educación desde la diversidad. Correo electrónico: diana.rodriguez.p@gmail.com

4 Miguel Alberto González González. Asesor de la tesis Universidad y Diversidad Cultural. Diálogos Imperfectos

5 El titulo de la investigación es inspirado del libro Diálogos Imperfectos del Maestro Silvio Sánchez Fajardo, quien se desempeñó como Docente, investigador y Rector de la Universidad de Nariño. 


\title{
University and Cultural Diversity. Imperfects Dialogues
}

\begin{abstract}
This article derives from the research denominated University and Cultural Diversity. Imperfect Dialogues, in which we asked on the senses cultural diversity that are being built / mobilizing students and teachers of ninth semester degree program in mathematics at the University of Nariño. To give answers to the question of the research, it has been developed the methodology based on hermeneutical - collective that proposes to reveal the senses and the meanings of the subject trough knowledge dialogue; the techniques used for collecting information were: documental analysis, depth interviews with key informants and discussion groups, the instruments designed were subjected by experts on the matter, by pilot test, and the analysis of the information has been realized by inductive categorization derived of the triangulation process information between sources and techniques utilized. The main findings of the research show that the senses of cultural diversity are mobilizing students and teachers revolve around following aspects: one emphasis racial ethnic of the cultural diversity, diversity seen as deficit or limitation, multicultural stance led to respect for difference, a contradiction between the institutional position and the demands of the national education system and a challenge against that acquires real meaning cultural diversity in education and can turn them into new systems of taxation and control.

Keywords: Diversity, cultural diversity, education, multiculturalism, interculturalism.
\end{abstract}

\section{A manera de introducción}

El presente artículo se deriva del proyecto de investigación titulado: Universidad y Diversidad Cultural. Diálogos Imperfectos, desarrollado como parte de la Maestría en Educación desde la Diversidad de la Universidad de Manizales y articulado al Macroproyecto Sujetos y Diversidad. El objetivo general del estudio fue comprender los sentidos de diversidad cultural que se están construyendo/ movilizando en los estudiantes de último semestre y docentes del programa de Licenciatura en Matemáticas de la Universidad de Nariño, pregunta derivada del análisis del estado del arte a nivel internacional, nacional y regional (Alonso, Navarro, Lidón, s,f; Castro, 2009; Del Arco, 1999; Gil Juarena, 2007; Llaquinao, 2009; Osorio, 2007; Rodríguez, 2008; Rodríguez, 2005; Ojeda y cols, 2012; etc.) que evidencia la necesidad de fortalecer el tema de la diversidad cultural como parte de los procesos de formación de los futuros docentes y a su vez refleja la posición personal de las autoras frente a la necesidad de cuestionar las bases sobre las cuales se construyen y validan los saberes y conocimientos desde los contextos educativos.

La investigación desarrollada es de carácter cualitativo y tiene como enfoque la Hermenéutica Colectiva, que de acuerdo con Ghiso (2000) permite develar los sentidos y significados de los sujetos que participan del proceso investigativo, aspecto clave en el presente proceso investigativo en el que se busca comprender precisamente esos sentidos de diversidad cultural presentes en los estudiantes y docentes del programa de Licenciatura en Matemáticas, a través del análisis de las concepciones, interpretación de las 
posiciones y el reconocimiento de las condiciones curriculares que facilitan $u$ obstaculizan la construcción/movilización de dichos sentidos.

Para el análisis y discusión de los hallazgos se construyó un marco teórico con base en los conceptos de cultura, diversidad cultural, multiculturalidad, interculturalidad y modelos de abordaje de la diversidad cultural elementos que permitieron una lectura amplia de los resultados encontrados.

\section{La razón de ser e importancia del tema}

\section{El acto de educar y de educarse sigue siendo en estricto sentido un acto político y no sólo pedagógico.}

Paulo Freire, $(1992,17)$

El abordaje de un tema como la diversidad cultural en los contextos educativos incluye toda una serie de elementos normativos y legales que lo justifican aunque no se reduce a ellos ya que es necesario reconocer elementos de tipo histórico, epistémico y político que nos permiten considerar que incluir la diversidad cultural en los procesos educativos no constituye una tarea fácil y mucho menos insignificante ya que mas allá de la obligación impuesta por la norma, su inclusión real se configura en una posibilidad de emancipación política y epistémica, que cuestiona las bases estructurales sobre las que se ha construido la relación entre poder y conocimiento dentro de nuestro sistema educativo.

Términos como inclusión, integración, diversidad, diferencia, interculturalidad, multiculturalidad, entre otros, han aparecido en la pizarra de la pedagogía con mayor fuerza a partir de los años 70 , provenientes principalmente de contextos europeos y anglosajones y no han surgido espontáneamente, sino que han sido el resultado de procesos iniciados desde dos vertientes, por un lado como respuesta a la demanda de reconocimiento que ciertos grupos denominados minoritarios han hecho a sus estados en todo el mundo, para que la sociedad garantice su acceso equitativo a los derechos, entre ellos a una educación que reconozca sus saberes propios y diversos, y por otro lado, tal como lo plantea Walsh (2008) esta emergencia del multiculturalismo que se hace especialmente evidente en las constituciones de los países latinoamericanos entre los que se incluye Colombia, ha coincidido con la expansión del proyecto neoliberal, ocultando una lógica en la que según la autora, la inclusión y la multiculturalidad se constituyen en un instrumento más que al mitigar los conflictos étnicos fortalece el proyecto de unidad nacional, en este sentido, cobra importancia desarrollar procesos de investigación y reflexión que desde varias posiciones y con una perspectiva crítica permitan develar el papel real que está jugando la diversidad y particularmente la diversidad cultural en los escenarios educativos.

Desde esta perspectiva es importante realizar la lectura de algunos planteamientos normativos que abogan por el abordaje de la diversidad cultural en Colombia, por ejemplo a partir de la Constitución Política de 1991 en donde se realiza el reconocimiento de nuestro país como un estado pluriétnico y multicultural, se han derivado una serie de herramientas jurídicas dirigidas a orientar el abordaje de la diversidad cultural en todos los contextos sociales, entre ellos, el educativo, es así como la Ley General de Educación (Ley 115 de 1994, 2) contempla como uno de sus fines "el estudio y la comprensión crítica de la cultura nacional y de la diversidad étnica y cultural del país, ello como fundamento de la unidad nacional $y$ de su identidad"; de igual manera, en el Plan Decenal de Educación (MEN, 2006, 16), documento que consolida las metas del país en este ámbito hasta el año 2016, se propone como uno de sus 
macroobjetivos "Garantizar pedagogías pertinentes para el reconocimiento de la diversidad étnica, cultural, de creencias y las demás formas asociativas que implican la interculturalidad y que hacen parte de la identidad nacional", para el caso de la educación superior, la normatividad también exige de parte de las instituciones tener en cuenta la universalidad de los saberes y la particularidad de las formas culturales existentes en el país y contribuir a la producción, desarrollo y transmisión del conocimiento y de la cultura universal y nacional (MEN, 1992).

Estos elementos normativos respaldan la importancia de abordar la diversidad cultural como categoría transversal a todos los niveles de educación en Colombia y de comprender el papel que ha venido desempeñando esta categoría en las prácticas educativas que se generan al interior de las instituciones, siendo de especial interés para el presente estudio reconocer el sentido que se le ha otorgado a la diversidad cultural en los procesos de formación que se brindan desde la educación superior a los estudiantes de licenciaturas a quienes se considera agentes clave en la producción y reproducción de saberes y conocimientos, puesto que ellos serán los futuros formadores en contextos marcados por una constante movilidad social, producto del conflicto sociopolítico de nuestro país y del constante intercambio cultural al que asistimos fruto del proceso mundial de globalización, situaciones que inevitablemente hacen de los escenarios educativos espacios caracterizados por la multiculturalidad, en donde confluyen multiplicidad de prácticas culturales que generalmente chocan con el orden establecido y a las que inevitablemente deberá enfrentarse el docente en su ejercicio profesional (Universidad de Nariño, 2009).

Al respecto, la revisión de estudios nacionales e internacionales relacionados con la educación dirigida a estudiantes culturalmente diversos destacan entre otras las situaciones de discriminación de que son víctimas estos estudiantes durante su proceso de aculturación en la escuela (Llanquinao, 2009), los prejuicios y estereotipos negativos que les atribuyen sus compañeros, la expresiones de discriminación sutil o manifiesta que reciben de sus compañeros y profesores (Ojeda y cols, 2012) y la falta de pertinencia de las metodologías empleadas por los docentes, tales como la aplicación de métodos expositivos tradicionales y la falta de dominio de la lengua local en casos de Etnoeducación y Educación Intercultural Bilingüe (Enciso citada por Castro, 2009) situaciones que dejan ver como problema de base que los futuros docentes se encuentran desorientados ante la diversidad cultural con la que se verán obligados interactuar pues su formación en el tema es mínima, cuando no inexistente, lo que les impide dar una respuesta adecuada a la situación que se les plantea, por lo cual, la formación específica en cuestiones relativas a la diversidad cultural se presenta como una demanda constante en los procesos de formación de los futuros docentes (Rodríguez, 2005) y para ello se requiere que la educación superior corrija y mejore la formación de sus profesores a fin de que sean capaces de asumir el reto de la diversidad cultural desde los distintos niveles educativos y para los diversos espacios geográficos que conforman el país.

Sin embargo, más allá de los marcos normativos y legales que abogan por el abordaje de la diversidad cultural en los procesos educativos de todo nivel, y de los vacios encontrados en los procesos de formación de los docentes que nos indican investigaciones previas, se debe reconocer la necesidad de que sean los mismos agentes del proceso educativo, estudiantes, directivos y en especial docentes quienes asuman una posición crítica frente a la forma como están seleccionando, construyendo y reproduciendo los conocimientos, puesto que ello tiene implicaciones de poder que mantienen la estructura social dominante o por el contrario contribuyen a transformarla, de acuerdo con Ghiso $(2000,4)$ 
Imágenes, nociones, ideas, opiniones, códigos y símbolos transmitidos desde los sectores hegemónicos, van desarrollando en los sujetos y grupos, con "ataduras", esquemas de conocimiento y acción que los sitúan en condiciones desiguales frente a la apropiación y construcción simbólica, debilitando su autonomía. ... Es, entonces, en relación a la construcción simbólica donde se están reorganizando y reconstituyendo las relaciones básicas de poder entre sujetos y grupos para dominarse, controlarse, explotarse 0 , por el contrario, encontrarse, dialogar, consensuar y concertar acciones.

En este orden de ideas, la apuesta por develar los sentidos de diversidad cultural que se están construyendo y movilizando en los futuros docentes, es el punto de partida de procesos que permitan primero en el escenario educativo y después en los demás escenarios sociales erradicar situaciones de discriminación racial, exclusión, desigualdad social y subalternidad (Albán, 2008) mediante el reconocimiento consiente de la alteridad, el respeto por la diversidad y la diferencia sin la pretensión de homogeneidad y sobre todo la transformación de las prácticas educativas tradicionales, que permita el reconocimiento del Otro como un legitimo interlocutor con quien sea posible establecer un diálogo genuino de saberes que permita reconocer y potenciar el valor de la diversidad, no como estrategia política de los proyectos hegemónicos sino como posibilidad humana de encuentro y enriquecimiento mutuo entre lo local y lo global.

\section{Lo que nos cuestiona}

¿Cuáles son los sentidos de diversidad cultural que se están construyendo/ movilizando en los estudiantes de noveno semestre y docentes del Programa de Licenciatura en Matemáticas de la Universidad de Nariño?

\section{Objetivo general}

Comprender los sentidos de diversidad cultural que se están construyendo/ movilizando en los estudiantes de noveno semestre y docentes del Programa de Licenciatura en Matemáticas de la Universidad de Nariño.

\section{Objetivos específicos}

- Analizar las concepciones de diversidad cultural que están construyendo/movilizando estudiantes y docentes.

- Interpretar las posiciones que asumen estudiantes y docentes ante la atención de la diversidad cultural en los contextos educativos.

- Reconocer las condiciones curriculares que posibilitan la construcción/ movilización de sentidos de diversidad cultural en los futuros docentes.

\section{Ecos en torno a la diversidad cultural}

Antes de retomar nuestra voz frente a los hallazgos encontrados en el presente estudio, dedicaremos este espacio a realizar un breve recorrido teórico que dé cuenta de las perspectivas a partir de las cuales enfocamos nuestra mirada en el proceso de recolección de información y que orientaron nuestras comprensiones de la misma.

\section{Algunas consideraciones sobre el concepto de cultura}

Para hablar de Diversidad Cultural, es importante en primer lugar definir lo que aquí comprenderemos por Cultura; la cultura, como objeto de estudio de la antropología ha sido comprendida desde varias perspectivas, siguiendo la clasificación presentada por Bodley (Citado por Zino, 2000, 2), podemos identificar las siguientes: 
Tabla 1.Clasificación de las definiciones de cultura

\begin{tabular}{|l|l|}
\hline \multicolumn{2}{|c|}{ Clasificación de las Definiciones de Cultura } \\
\hline Tópica: & La cultura consiste en una lista de tópicos o categorías, tales como organización social, religión, o economía \\
\hline Histórica: & La cultura es la herencia social, o la tradición, que se transmite a las futuras a las generaciones \\
\hline Comportamental: & La cultura es el comportamiento humano compartido y aprendido, un modo de vida \\
\hline Normativa: & La cultura son ideales, valores, o reglas para vivir \\
\hline Funcional: & $\begin{array}{l}\text { La cultura es la manera que los seres humanos solucionan problemas de adaptación al ambiente o a } \\
\text { la vida en común }\end{array}$ \\
\hline Mental: & $\begin{array}{l}\text { La cultura es un complejo de ideas, o los hábitos aprendidos, que inhiben impulsos y distinguen a la } \\
\text { gente de los animales }\end{array}$ \\
\hline Estructural: & La cultura consiste en ideas, símbolos, o comportamientos, modelados o pautados e interrelacionados. \\
\hline Simbólica: & La cultura se basa en los significados arbitrariamente asignados que son compartidos por una sociedad \\
\hline
\end{tabular}

De todas estas posibilidades y en coherencia con los propósitos que se han venido planteando para el presente proceso investigativo, se asumirá una perspectiva simbólica e interpretativista, mas particularmente se tomará la definición de cultura planteada por Geertz $(2005,51)$ quien a diferencia de concepciones antropológicas tradicionales como las derivadas del funcionalismo de Malinowsky o el Estructuralismo de Levi-Strauss, considera que "La cultura se comprende mejor no como complejos de esquemas concretos de conducta - costumbres, usanzas, tradiciones, conjuntos de hábitos-, como ha ocurrido en general hasta ahora, sino como una serie de mecanismos de control — planes, recetas, fórmulas, reglas, instrucciones (lo que los ingenieros de computación llaman "programas") - que gobiernan la conducta”. Para Geertz, esta concepción de la cultura desde el punto de vista de los mecanismos de control, parte del supuesto de que el pensamiento humano es fundamentalmente social y público.

Lo importante, señala Geertz (2005, 51), es comprender la cultura como:

producción de sentidos, de manera que también podemos entender a la cultura como el sentido que tienen los fenómenos y eventos de la vida cotidiana para un grupo humano determinado...La cultura, como trama de significados y desarrollos simbólicos, se compone de un complejo grupo de complicaciones, sutilezas y matices, que pueden ser analizadas sólo desde una fase arqueológica de estudio: un análisis capa a capa de la cultura para enfrentar los problemas fundamentales.

Perspectiva a partir de la cual se comprenderá la categoría de cultura en el presente estudio.

\section{Diversidad y diversidad cultural: tras las huellas de su discurso}

Una vez planteado el concepto de cultura, la tarea es acercarnos a lo que entenderemos por diversidad en general y diversidad cultural en particular; de manera general partiremos por comprender que diversidad es "entender la variedad que produce lo ecológico, lo biológico, lo familiar, lo escolar, lo cultural y lo social" (Cárdenas, 2011, 3), lo que implica que en cualquier contexto y entorno la diversidad se hace presente.

Es importante diferenciar la diversidad de otros conceptos relacionados con los que suele confundirse entre los que cobra especial relevancia el concepto de desigualdad, al respecto señala Muñoz (Citado por Hernández, 2010, 9) que

por diversidad entendemos todo aquello que hace a las personas y a los colectivos diferentes, y por desigualdad todo aquello que establece jerarquías en el saber, el poder o la riqueza de las personas o colectivos 
... La diversidad se referirá a factores físicos, genéticos, personales y culturales ... La desigualdad se referirá sobre todo a factores sociales, económicos, políticos ... En educación hablaremos de personas diferentes en cuanto a capacidades, estilos, ritmos, motivaciones, valores culturales ... y hablaremos de desigualdad en situaciones que habremos definido convencionalmente que son de desventaja o de carencia en relación a otras personas o colectivos ... Así pues, todos y todas somos diferentes (diversos) y todos y todas padecemos de alguna situación de desventaja o carencia, independientemente de que decidamos compensarla o no.

Por su parte cabe destacar los planteamientos de Gimeno (1996, Citado por Hernández, 2010, 5) para quien la diversidad alude a la "circunstancia de ser distinto y diferente, pero también a la de ser desigual, lo que no sólo se manifiesta en una forma de ser variada, sino de poder ser, de tener posibilidades de ser y de participar en los bienes sociales, económicos y culturales" para este autor, lo diverso lo contraponemos a lo homogéneo y "lo desigual lo confrontamos con la nivelación y ésta es una aspiración básica de la educación que es, capacitación para poder ser". Por lo tanto en coherencia con la perspectiva del presente estudio y siguiendo con lo planteado por Gimeno, al hacer referencia a la diversidad no podemos perder de vista que

las relaciones jerárquicas de poder entre hombres y mujeres, normales y anormales, mayorías $y$ minorías, ricos y pobres, propios $y$ extraños, incluidos y excluidos... han marcado distancias en el trato y en las posibilidades de realización de sus proyectos de vida personal y social, desencadenando paulatinamente una violencia implícita o explícita, aceptada o no, cuya expresión evidencia el sentido ideológico que conllevan determinadas prácticas socioculturales (Gimeno, Citado por Hernández, 2010, 5).

Los planteamientos hasta aquí presentados, nos permiten comprender la diversidad como una categoría a partir de la cual se posibilita realizar lecturas de la manera como se establecen formas de organización social, de distribución de poderes e incluso de construcción y reproducción de conocimiento en relación a las diferencias biológicas, sociales o culturales de determinados individuos, grupos o colectivos.

\section{Acerca de la diversidad cultural}

Cuando hablamos de Diversidad Humana, debemos reconocer que existen multiplicidad de categorías desde donde podemos enfocar nuestra mirada, la diversidad se produce en los más diversos campos: social, cultural, filosófico, religioso, moral y político. En relación a lo cultural, retomaremos la definición realizada por la UNESCO en el año 2001, tras la Declaración Universal de la Diversidad Cultural, no porque sea esta la postura desde la que asumiremos esta categoría sino porque se reconoce el impacto que tienen estas declaraciones sobre las políticas de Estado y particularmente las políticas educativas, puesto que se trata de un documento avalado por la comunidad internacional, que realiza el reconocimiento de este tipo de diversidad y establece las conductas a las que obliga. En el Artículo 1 de esta declaración se plantea que

La cultura adquiere formas diversas a través del tiempo y del espacio. Esta diversidad se manifiesta en la originalidad y la pluralidad de las identidades que caracterizan los grupos y las sociedades que componen la humanidad. Fuente de intercambios, de innovación y de creatividad, la diversidad cultural es, para el género humano, tan necesaria como la diversidad biológica para los organismos vivos. En este 
sentido, constituye el patrimonio común de la humanidad y debe ser reconocida y consolidada en beneficio de las generaciones presentes y futuras (UNESCO, 2001, 4).

De acuerdo con Batallán y Campanini (2008) si bien la propuesta de esta Declaración era dar un giro conceptual y valorativo al hablar de la defensa de la diversidad cultural, se observa cómo ésta mantiene la sombra de la intencionalidad clasificatoria de grupos y poblaciones con las cuales se acuñó el término en el siglo $\mathrm{XVI}$, asimismo se pone en evidencia la orientación funcionalista que se esconde tras el uso de este concepto al declarar que la cultura "se encuentra en el centro de los debates contemporáneos sobre la identidad, la cohesión social y el desarrollo de una economía fundada en el saber" (UNESCO, 2001, 4). Por otra parte Batallán y Campanini $(2008,161)$ asumen el concepto desde una perspectiva crítica frente a la orientación moral que se le ha otorgado a la diversidad cultural

En el tratamiento pedagógico del respeto a la diversidad que realizan los diseños curriculares se amalgaman argumentos teóricos y didácticos de orientación funcionalista que reducen este postulado a un plano meramente moral, obturando la potencialidad analítica del relativismo para comprender y elaborar el conflicto inherente a las prácticas democráticas en la escuela... la potencialidad crítica del precepto relativista actúa predominantemente en el plano normativo de control a los comportamientos, debido a una aparente paradoja que sostiene, por un lado, la obligatoriedad de la escuela en difundir y sostener una norma universalmente válida para todos y por otro, en su misma obligación de respetar y hacer respetar la diferencia cultural de grupos -"otros"- que dentro de ella son supuestamente portadores de una cultura particular.
En este punto las autoras nos hacen reconocer una seria contradicción en el discurso de la diversidad instaurado por una sociedad y una época que promueve principios de universalización, internacionalización u homogeneización. Otros autores como Magendzo $(2006,11)$, llaman nuestra atención sobre las implicaciones sociales y políticas de la diversidad cultural en el contexto particular de América Latina, para este autor la diversidad presupone cuestionar el conformismo, ser crítico ante las desigualdades sociales, las injusticias y buscar cambios estructurales que lleven a una verdadera transformación de la realidad, puesto que "el mensaje de la diversidad no es neutro, asumir la diversidad como relación significa, por de pronto, aceptar la inter y multiculturalidad como un nuevo paradigma de organización social en donde conceptos como la responsabilidad social, la ciudadanía activa, el empoderamiento, la participación ciudadana, la democracia deliberativa, se redefinen y vigorizan".

\section{Miradas a la diversidad cultural}

\section{La diversidad vista desde el multiculturalismo y la multiculturalidad}

En la discusión en torno a la diversidad cultural se han propuesto diversas miradas, entre ellas la multiculturalidad que implica un reconocimiento de la existencia de diferentes culturas, de acuerdo con Catherine Walsh $(2008,51)$ la multiculturalidad

es un término descriptivo que encuentra sus raíces en los países occidentales y en las bases del estado liberal, y su afán de tolerancia e igualdad. Hace referencia a la multiplicidad de culturas que existen dentro de una sociedad sin que necesariamente tengan una relación 
entre ellas. Pero además de obviar la dimensión relacional. Oculta la permanencia de las desigualdades sociales, dejando intactas las estructuras e instituciones que privilegian a unos sobre Otros.

En este sentido, la multiculturalidad no cuestiona las condiciones de desigualdad en las que se construye y reproduce el conocimiento y se dan las formas de relación entre sujetos sino que invita a un reconocimiento, respeto y tolerancia de la diversidad cultural, de tal manera que no permite una verdadera transformación de las estructuras desde las que se ha pensado y abordado la diversidad cultural, manteniendo un orden socialmente establecido que es conveniente para unos pocos que ostentan poder. Por su parte, para Villa y Grueso (2008, 29-30) la multiculturalidad y el multiculturalismo, permiten entonces

reconocer que los otros son diferentes, pero como diferentes que son, deben ser encerrados a través de la "forma de decir" que se dispone para legitimar las demarcaciones que conllevan la diferenciación; es una condena demarcativa para establecer distancia, un estado de reducción para la acción que condena, un encierro que silencia a los otros. Todo lleva a pensar, que por el solo hecho de reconocer la diferencia no se resuelven las desigualdades, porque el otro se mantiene a la distancia a través de los encierros que posibilita una demarcación para la acción de etiquetar o solo poner rótulos que condenan a los otros a quedarse allá...

Walsh $(2008,50)$ también llama la atención sobre como desde el multiculturalismo se reconoce al Otro siempre y cuando se mantenga circunscrito en la insularidad asignada dentro del orden de la nación, y en sí, del orden global. "Tal reconocimiento emana no de la gente, sino de la "buena" voluntad y del poder del Estado y de la sociedad dominante. No cuestiona las bases ideológicas (o coloniales y racistas) de la nación; más bien imagina la nación como un archipiélago donde las etnias son islas particulares acotadas y comunicadas por las aguas universales de lo nacional", es así como la incorporación o inclusión de la diversidad como otredad dentro del aparato estatal, no conduce a la creación de sociedades más justas o igualitarias, y tampoco enfrenta el racismo y racionalización que se han enraizado en las estructuras y sistemas del poder.

\section{La diversidad vista a través de los lentes de la interculturalidad}

A diferencia de la multiculturalidad, la interculturalidad tiene sus orígenes y antecedentes no en el Estado, sino en las discusiones políticas puestas en escena por los movimientos sociales, además, no propone únicamente el reconocimiento de la diversidad cultural como se hace desde la perspectiva multicultural sino que plantea la interrelación de culturas y se pregunta por los sentidos de los otros. Desde esta perspectiva es necesario reconocer que en el encuentro de diferentes formas de pensar, sentir, habitar y representar el mundo se pone en crisis lo establecido $y$ "en este caso la interculturalidad se ve como una posibilidad que pone de relieve la disposición - construcción de estrategias políticas, económicas y sociales que permitan la emergencia de lo silenciado, olvidado y devaluado por las prácticas hegemónicas de quienes han generado formas de homogeneización cultural" (Villa y Grueso, 2008, 25).

Siendo así la interculturalidad, no es sólo una forma de establecer relaciones entre saberes distintos, sino un proyecto político que cuestiona los lugares de poder desde los cuales se producen las representaciones mismas acerca de lo que es, y lo que no, reconocido como conocimiento. El reflexionar sobre la educación desde una perspectiva intercultural puede convertirse entonces en una posibilidad para romper los moldes desde los que se ha 
pensado el significado de la diversidad cultural, al reconocer que no existe un solo tipo de saber, un solo tipo de conocimiento sino que por el contrario hay diferentes formas culturales de producción de conocimiento, en este sentido

propender por una educación intercultural no sólo implica una nueva manera de educar de manera diferente a los sujetos, sino una posibilidad de entablar nuevos diálogos en el contexto de la interculturalidad, y ello excede (aunque no desconoce) lo que se ha entendido como etnoeducación. La educación intercultural convoca a un nuevo tejido de relaciones entre sujetos individuales y colectivos de múltiples y disímiles matrices culturales; lo cual significa que sólo será posible si transformamos nuevamente las representaciones sociales vigentes, de tal manera que se cuestionen y transformen las relaciones de poder/dominación que han subordinado unos saberes y han ubicado otros en el lugar de saberes hegemónicos (Rojas, S,f, 9).

Las definiciones hasta aquí presentadas, nos muestran cómo se ha venido redefiniendo el objeto de estudio de la diversidad cultural, pasando de un interés por cuantificar etnias, sus lenguas y costumbres, a un reconocimiento de la diferencia desde un plano axiológico y actitudinal -multiculturalidad- para finalmente realizar una lectura más compleja de la realidad donde hablar de diversidad cultural, implica cuestionar los diferentes procesos sociales, políticos, culturales, económicos e históricos desde los cuales se han establecido desigualdades e inequidades en relación a la diversidad y la diferencia.

\section{Las rutas de la diversidad en los contextos educativos: Modelos de atención a la diversidad cultural}

De acuerdo a los planteamientos de Rodríguez (S, f) como parte del recono- cimiento de la existencia de la diversidad cultural en los contextos educativos, se han derivado diferentes propuestas de atención a la misma tales como el modelo asimilacionista, que pretende borrar las diferencias haciendo que el estudiante se adapte a las pautas de la cultura dominante, el modelo compensatorio que aborda las diferencias como un déficit y por ello desarrolla programas que buscan nivelar a los estudiantes en aquellos aspectos que consideran como falencias y el modelo segregacionista que pretende que las personas diferentes asistan a escuelas especiales para ellos. Asimismo se han planteado propuestas positivas como el pluralismo cultural, la orientación multicultural o la educación no racista en los cuales se interpreta la diferencia como una posibilidad de aprender y compartir nuevas experiencias pero donde más que reconocer la diversidad y propiciar condiciones para compartir saberes se pretende asumir una postura de tolerancia ante la misma. Finalmente, en los últimos años han tenido mayor auge propuestas como la educación intercultural y especialmente en las comunidades indígenas, la propuesta de una educación propia.

\section{El camino a recorrer}

\section{Tanto los sujetos, como el mundo son construidos en la interacción creativa, dialógica e intencionada}

(Ghiso, 2000, 5).

En la figura 1. se presenta un esquema que resume la metodología empleada en la presente investigación ${ }^{6}$ :

La investigación es de corte cualitativo y se enmarca en la Hermenéutica Colectiva, que de acuerdo con Ghiso $(2000,9)$ es "el camino que se utiliza para tematizar, relacionar, contextualizar, comprender y pro-

6 Figura 1. Elaboración propia: Metodología del proceso de investigación. 


\section{Plumilla Educatival}

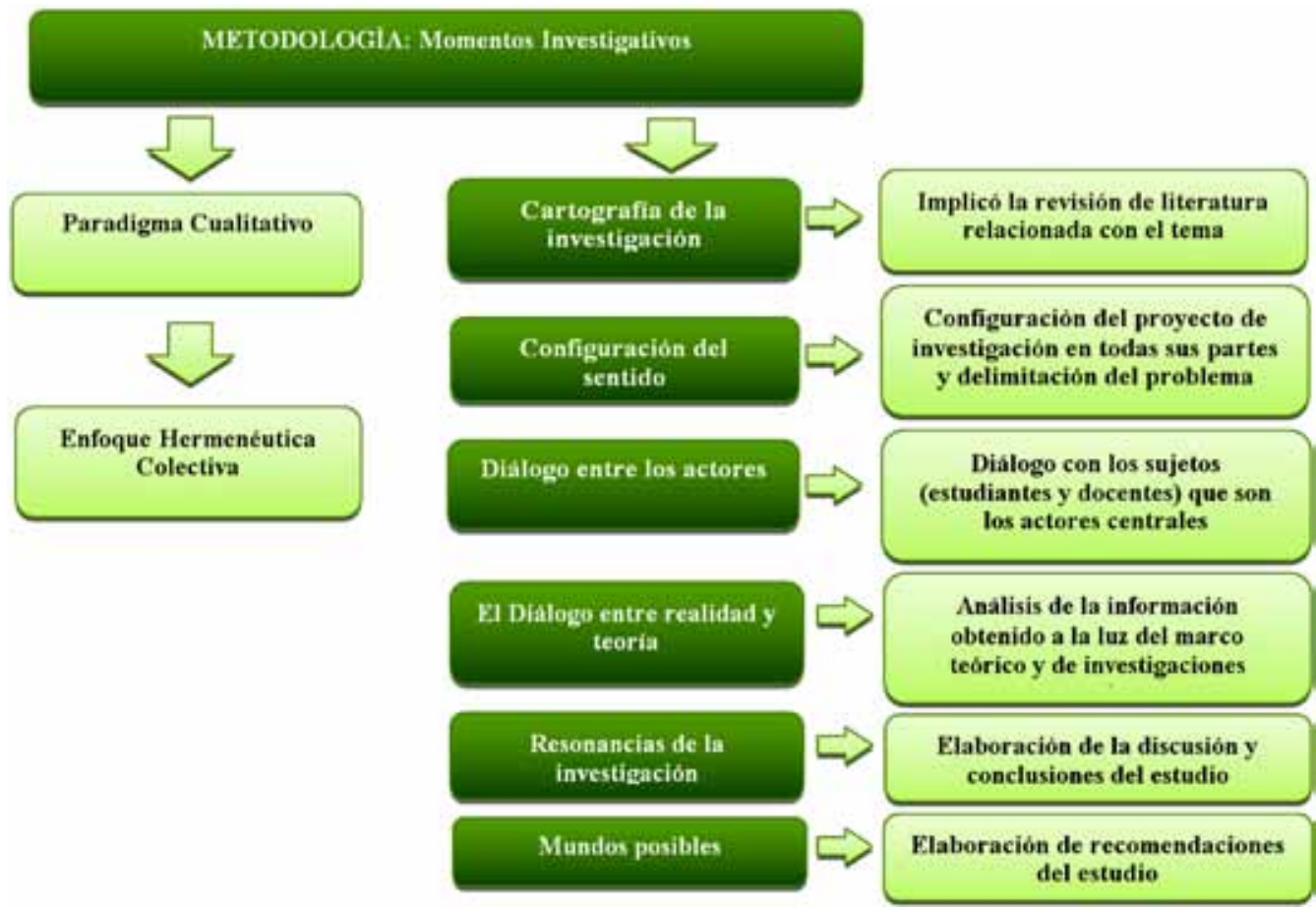

Figura 1. Esquema que resume la metodología empleada en la presente investigación.

blematizar esas manifestaciones vitales... es comprender, a partir de experiencias, las partes y la totalidad de la vida desde sus manifestaciones de vida a lo largo de la historia de un individuo, de un grupo o de una institución social". Se reconoce la hermenéutica colectiva como herramienta metodológica para nuestro proceso investigativo, puesto que es coherente con la necesidad -identificada en este procesode establecer un diálogo de saberes entre los sujetos que hacen parte del contexto universitario, diálogo que encuentra en las experiencias de vida una herramienta valiosa que permite develar los sentidos y significados de los sujetos que participan del proceso, reconociendo la importancia de los tiempos, espacios y escenarios en donde acontecen estas experiencias y que condicionan su quehacer potenciándolos o depotenciandolos.

\section{Hallazgos de la investigación}

A continuación se presentan los principales hallazgos del proceso investigativo organizados en tres categorías acordes a los objetivos planteados: concepciones de diversidad cultural, posiciones ante la diversidad cultural y condiciones necesarias para la emergencia y movilización de sentidos de diversidad cultural, en cada una de las cuales se presenta la posición de la universidad a nivel institucional, la de los estudiantes y la de los docentes.

\section{Concepciones de diversidad cultural}

¿Qué dice la Universidad como institución? 
Para comprender el sentido que adquiere la diversidad cultural para la Universidad de Nariño como institución, se realizó el análisis de tres documentos claves en su direccionamiento estratégico y curricular como son: el Plan de Desarrollo Institucional 2008-2020 (PDI), el Proyecto Educativo Institucional (PEI), y el Proyecto Educativo Pedagógico del Programa de Licenciatura en Matemáticas (PEP), documentos que se han venido reestructurando como parte del proceso de Reforma Profunda iniciado en el año 2008 bajo el liderazgo del entonces rector Silvio Sánchez Fajardo y que propuso como lema el diálogo entre la Universidad y la Región.

Este análisis permite reconocer las concepciones de diversidad cultural y otras categorías relacionadas que se están desarrollando a nivel institucional a partir del proceso de reforma, de las cuales se destaca lo planteado en el PEI $(2009,16)$ respecto a que "la Universidad de Nariño en su nueva Misión entiende la cultura desde el reconocimiento de las relaciones de poder que producen valores, concepciones y formas de conocimiento", lo que indica que se viene dando un cuestionamiento frente a la relación entre poder y conocimiento como un elemento fundamental en la generación de inequidades y desigualdades sociales y las posibilidades de ejercicio de autonomía y participación de los bienes sociales, económicos, culturales y epistémicos que tienen los sujetos y comunidades culturalmente diversas, cuyas posibilidades de ser y vivir en la mayoría de los casos no concuerdan con las estructuras hegemónicas que reproducen las instituciones educativas a todo nivel.

De igual manera cuando se alude al abordaje de la diversidad cultural desde la universidad se evidencia una constante referencia a la multi e interculturalidad, en todos los documentos se reconoce la Región Nariñense como un espacio multicultural, debido a que "tiene una ubicación estratégica porque se encuentra entre el pulmón del mundo, en el que confluyen el
Pacífico biogeográfico, la Amazonía, los Andes; y la cuna de la identidad cultural de la mayoría de pueblos originarios, que la sitúan como frontera internacional de Colombia con Suramérica" (PEI, 2009, 15), lo que implica que la Universidad se constituye en un escenario donde lo multicultural se hace presente y la multiculturalidad se reduce a la presencia de varias culturas en un espacio determinado sin que necesariamente se presente interacción entre ellas.

Por su parte, la interculturalidad se define como un principio que supone: "el diálogo entre las culturas en un plano de transversalidad, el respeto por la diferencia, la alteridad, el conocimiento y reconocimiento de sus cosmovisiones, y la interacción en el marco de la complementariedad" (PEI, 2009, 9), definición que otorga a la interculturalidad el matiz de un principio axiológico, pues si bien plantea un diálogo de saberes, hace énfasis en el respeto por el Otro y el reconocimiento de su diferencia, concepción que se relaciona con lo propuesto por Batallán y Campanini $(2008,161)$ quienes consideran que "en el tratamiento pedagógico del respeto a la diversidad que realizan los diseños curriculares se amalgaman argumentos teóricos y didácticos de orientación funcionalista que reducen este postulado a un plano meramente moral, obturando la potencialidad analítica del relativismo -cultural- para comprender y elaborar el conflicto inherente a las prácticas democráticas en la escuela".

Por su parte en el PEI se "reafirma la voluntad de educar en y para la interculturalidad, por cuanto los seres humanos se identifican a través de las múltiples formas imaginarias y simbólicas que dan sentido a su modo de pensar, de ser y estar en el mundo...esto supone superar el etnocentrismo cultural, científico y social para integrar al conocimiento académico, los saberes culturales y sociales" (PEI, 2009, 26), asimismo en el PDI, se apuesta por la construcción de la categoría de Pensamiento Propio comprendido como 
“construcción compleja e hibridada que no rechace los aportes de la ciencia europea, leída críticamente, y que integre de manera creativa, los aportes de los ancestros, tanto indígenas como afrodescendientes" (PDI, 2008, 26), planteamientos que se acercan más a lo que aquí comprendemos por interculturalidad, categoría que de acuerdo con Villa y Grueso $(2008,25)$ no propone únicamente el reconocimiento de la diversidad cultural sino que plantea la interrelación de culturas y se pregunta por los sentidos de los otros, permitiendo la confluencia de formas de pensar, sentir, habitar y representar el mundo que ponen en crisis lo establecido y, generan la necesidad de construir estrategias políticas, económicas y sociales "que permitan la emergencia de lo silenciado, olvidado y devaluado por las prácticas hegemónicas de quienes han generado formas de homogeneización cultural".

Sin embargo, y probablemente por el hecho de que las reformas en educación son procesos paulatinos que se presentan a mediano y largo plazo, los mismos documentos presentan elementos que cuestionan la verdadera postura de la universidad frente a la integración de otros saberes culturales y sociales con sus formas tradicionales de construir y reproducir conocimiento, es así como tanto en el PEI como en el PDI se menciona explícitamente la necesidad de una validación científica del conocimiento y los saberes, al respecto se afirma que "debe existir voluntad para la ciencia como el cuestionamiento permanente que genere la capacidad de encontrar la unidad en la diversidad" (PEI, $2009,11)$ y que "la diversidad de pensamientos, permite mirar el acontecimiento de manera clara y científica..." (PDI, 2008, $36)$, lo cual entra en contradicción con la propuesta de diálogo de saberes constantemente expuesta en estos documentos, puesto que si se continua concibiendo la ciencia como único dispositivo que valida el conocimiento, este diálogo termina por presentarse como una falacia al no garantizar las condiciones que posibiliten que el Otro y su conocimiento/saber sea genuinamente reconocido y escuchado, y no simplemente se simule escuchar para demostrar el cumplimiento de un principio moral. De igual forma estas concepciones del conocimiento, develan una postura cuya pretensión final es lograr la unidad en la diversidad, sin dejar abierta la posibilidad a otras formas de conocimiento capaces de aceptar la diferencia y la complejidad, sin pretender aniquilarlas en búsqueda de la unidad, la homegeneidad y los dispositivos de control que esto posibilita.

Las concepciones de diversidad cultural hasta aquí presentadas, hacen evidente el énfasis en la dimensión étnica que a nivel institucional se le otorga a esta categoría específicamente en lo que respecta a comunidades indígenas y afrocolombianas, aunque cabe destacar que dentro del PEP del Programa de Licenciatura en Matemáticas (2010), se reconocen otras manifestaciones de diversidad cultural que van más allá de lo étnico y tiene en cuenta variables como el género, la clase y el grupo etareo al que pertenecen los estudiantes, lo que indica que se está ampliando el espectro sobre lo que se comprende por diversidad cultural y sus implicaciones en los procesos de enseñanza-aprendizaje.

De manera general, los documentos analizados indican que se han dado importantes pasos en el reconocimiento de la diversidad cultural y la importancia de su inclusión en la formación de los futuros profesionales, sin embargo y bajo los lineamientos teóricos adoptados para la presente investigación, a nivel institucional se requiere de una posición más crítica frente a la construcción del conocimiento, desde una dimensión en la que la denominada multi o interculturalidad, no sólo se presente como una forma de establecer relaciones entre saberes distintos, sino como un proyecto político que cuestione los lugares de poder desde los cuales se producen las representaciones mismas acerca de lo que es, y lo que no reconocido como conocimiento, proyecto al que 
la Universidad se ve convocada más aún cuando reconoce la característica multicultural del contexto donde tiene lugar.

\section{La voz de los estudiantes}

Frente a las concepciones de diversidad cultural manifestadas por los estudiantes de Licenciatura en Matemáticas, se encuentra que la diversidad en general se concibe como variedad y diferencia, lo cual entra en consonancia con lo planteado por Cárdenas $(2011,3)$ para quien la diversidad es "entender la variedad que produce lo ecológico, lo biológico, lo familiar, lo escolar, lo cultural y lo social"; por su parte la diversidad cultural se concibe como "las diferentes formas de observar, expresarse, ver el mundo, pensar y construir conocimiento" (Estudiante 1, 2012) concepción que se relaciona con los planteamientos de Squella (citado por Magendzo, 2006, 11), para quien la diversidad, "es un hecho fáctico de toda sociedad en la que existen una variedad no coincidente de creencias, convicciones, sentimientos y puntos de vista acerca de asuntos que se repuntan importantes como el origen y finalidad de la vida humana; la relación del hombre con una posible divinidad; la idea de vida buena y los medios necesarios para alcanzarla; la organización y distribución del poder, etc.". Asimismo se encuentra que los estudiantes asocian la diversidad cultural principalmente con los grupos étnicos, aunque se reconocen otras expresiones de ésta relacionadas con los denominados grupos urbanos e incluso con las diferencias de género, lo que indica que en coherencia con los planteamientos del PEP (2010) los estudiantes vienen construyendo una concepción que supera posturas tradicionales que relacionan la diversidad cultural con categorías étnicas o raciales, aunque se continua haciendo énfasis en estas.

\section{La voz de los docentes}

En coherencia con lo planteado por los estudiantes, los docentes del Programa de Licenciatura en Matemáticas que participaron de la investigación, conciben la diversidad cultural como un "conjunto de conocimientos, saberes, expectativas y significados distintos que circulan y cambian de una cultura a otra" (Docente $1,2012)$ y la relacionan específicamente con las distintas formas de aprender matemáticas, asimismo se plantea que desde el Programa de Matemáticas se promueve la diversidad cultural entendiendo "que cada grupo cultural del mundo crea unos conocimientos, unos saberes, tiene unas expectativas distintas frente a la vida, tiene unas experiencias religiosas distintas". (Docente 2, 2012)

En este punto es importante destacar que desde el Programa de Licenciatura en Matemáticas se ofrece a los estudiantes de noveno y décimo semestre las materias de Educación y Cultura I y II que pretenden abordar las diferentes maneras de aprender matemáticas teniendo en cuenta las características culturales de los estudiantes, aspecto que vale la pena resaltar proviniendo de un área del conocimiento caracterizada por su amplia tradición científica y la búsqueda de validación y generalización de los conocimientos que produce; de acuerdo con lo manifestado por el docente de esta materia "la diversidad cultural se aborda desde una perspectiva antropológica destacando la importancia del significado que se le otorga a los conocimientos en una cultura determinada, de acuerdo a las necesidades que se presentan en ella" (Docente 1, 2012); concepción que entra en diálogo con la perspectiva de Geertz $(2005,51)$ para quien lo importante es comprender la cultura como "producción de sentidos... como el sentido que tienen los fenómenos y eventos de la vida cotidiana para un grupo humano determinado".

De igual forma se encontró que los docentes relacionan la diversidad cultural con problemáticas como el racismo y la discriminación por género, con lo que se reconoce que trasciende de los problemas académicos y de aula y se vincula a problemáticas sociales históricamente 
mantenidas como la discriminación y la exclusión.

\section{Posiciones ante la diversidad cultural}

\section{La mirada institucional}

La Universidad de Nariño reconoce la diversidad cultural de la región, los saberes locales y existe una apertura a un diálogo de saberes, esto se puede interpretar como un aspecto positivo, que indica reflexión del tema al interior de la institución y su inclusión en los diferentes documentos matrices, no obstante su materialización en las practicas de formación es un aspecto aún incipiente en la mayor parte de los programas académicos.

Asimismo, la universidad reconoce que existen presiones desde el sistema educativo que no permiten abordar la diversidad cultural, en este sentido, se evidencia una contradicción entre lo que la universidad desea formar desde su misión, visión y principios y las exigencias del gobierno nacional, "los sistemas de educación superior están presionados hacia el cambio por los mismos factores que movilizan al mundo globalizado, por ende, al sistema académico universitario se le exige formar profesionales que respondan a los requerimientos de índole neoliberal introducidos en los países latinoamericanos" (PEI, $2009,14)$, al respecto cabe preguntarse ¿Cuál es el papel y el compromiso que tiene la educación superior frente a la diversidad cultural? ¿La diversidad cultural es un concepto museo? ¿Cuál es la respuesta ante esas presiones del Estado? ante estos interrogantes posiblemente no encontremos respuestas pero es importante que se inicie un proceso de reflexión.

Un aspecto que llama la atención es el reconocimiento de la diversidad a partir de sus limitaciones y de la vulnerabilidad de los grupos diversos "para el Proyecto Educativo Institucional -PEI- el fundamento humano, social y cultural involucra la formación de una cultura de la inclusión de grupos humanos y de personas caracterizadas por alguna limitación de carácter físico, económico, social, étnico y cultural, que se traduzca en todas las actividades Institucionales incluyendo las de orden pedagógico" (PEI, 2009, 26 -27), esto a su vez tiene implicaciones en las practicas de formación que se lleven a cabo, si la diversidad es considerada como una limitación posiblemente las estrategias que se desarrollen para su abordaje sean de tipo compensatorio, como lo plantea Rodríguez (S, f, 1390) "existen algunos modelos que pretenden afirmar la cultura hegemónica dominante, es decir, modelos en los que la diversidad cultural es considerada como un déficit y en su abordaje prima el interés por asimilar, compensar o segregar a los estudiantes culturalmente diversos".

Por último, desde el PEP el abordaje de la diversidad cultural tiene implicaciones para el proceso de formación de los futuros licenciados, tal como se expresa en el documento "en el proceso formativo y en el devenir de las prácticas científicas intervienen diversos factores que responden a exigencias sociales, culturales, ideológicas, políticas, filosóficas, etc... Este proceso está determinado por parámetros axiológicos provenientes de la concepción del hombre histórico sobre la realidad, la construcción de sentido de vida y el uso de ese mismo conocimiento para un proyecto de vida social, económica y cultural" (2010, 12), lo anterior nos permite comprender que la configuración de los diferentes factores en el proceso de formación se va a ver reflejado en la configuración del sentido de vida que haga cada sujeto y en su construcción de un proyecto de vida, que seguramente tendrá implicaciones en su rol como docente.

\section{La mirada de los estudiantes}

Los estudiantes reconocen que como futuros docentes se verán enfrentados a contextos diversos, donde confluyen múltiples miradas de ver y entender el mundo, por ende reconocen como un 
aspecto importante el abordaje de la diversidad cultural dentro de sus procesos de formación, tal como lo afirma uno de uno de los estudiantes "es importante, porque vemos que en el aula de clase hay muchos estudiantes que tienen diferentes formas de pensar, de ver la vida, entonces, para trabajar un cierto concepto matemático, debemos tener en cuenta estos saberes" (Estudiante 4, 2012), afirmación que refleja la conciencia que tienen los estudiantes frente a la existencia de diferentes formas de concebir el mundo y de construir conocimiento y su incidencia en la enseñanza de las matemáticas.

Asimismo consideran que reconocer la diversidad cultural en el aula facilita la identificación de las metodologías que se van a emplear para la enseñanza, percibiéndola como un aspecto positivo para potenciar el proceso de enseñanza - aprendizaje, de igual forma la conciben como una oportunidad que posibilita la construcción de conocimiento social, esto coincide con lo planteado en el Foro Latinoamericano de Políticas Educativas -FLAPE- donde se afirma que "la oportunidad que ofrece reflexionar acerca de una educación intercultural es romper los moldes desde los que se ha pensado el significado de la diversidad cultural y lo que significa educar interculturalmente, reconociendo por ejemplo, que no existe un sólo tipo de saber, un sólo tipo de conocimiento sino que por el contrario hay diferentes formas culturales de producción de conocimiento" (FLAPE, 2005 citado por Castro, 2009, 368)

Igualmente los estudiantes hacen una valoración positiva del abordaje de la diversidad cultural en su proceso de formación y reconocen que antes los docentes no tenían esta oportunidad, además identifican la necesidad de que desde la Universidad se posibiliten estos espacios no sólo para ellos como estudiantes sino para aquellos docentes que están en ejercicio y que no han recibido ningún tipo de formación al respecto. Además reconocen que el abordaje de la diversidad cultural en el aula como futuros docentes puede facilitar la convivencia escolar, al permitir que los procesos de enseñanza aprendizaje sean más participativos, tomando en cuenta los saberes previos de los estudiantes a fin de no llegar a imponer conocimientos y dando la palabra al estudiante para plantear otras formas de construir conocimiento, como lo expresa uno de los estudiantes "como futuros docentes estamos enfrentados a una cierta comunicación con nuestros alumnos... los alumnos nos pueden dar otra solución a nuestro problema, o sea que los alumnos pueden plantear un problema y este alumno lo resolvió de una forma y este otro alumno lo resolvió de otra forma y eso enriquece el proceso matemático lo que permite un mejor aprendizaje" (Estudiante 2, 2012).

En este sentido se observa como los estudiantes se visualizan en su rol como docentes y resaltan la importancia de la diversidad cultural en el proceso de enseñanza aprendizaje como un aspecto que lo enriquece y lo facilita, asumiendo desde ya una responsabilidad con el abordaje de la misma, lo cual pone en evidencia la potencialidad del abordaje de la diversidad cultural como posibilitadora de rupturas frente a la educación tradicional que se mantiene en las instituciones educativas, al permitir reconocer la voz y los conocimientos de los Otros, lo que se constituye en un elemento enriquecedor para el contexto educativo.

Por otra parte, la diversidad cultural se la asume como el respeto de los conocimientos de las diferentes culturas para asociarlos a los conocimientos de la cultura occidental, esto refleja una posición que busca conciliar unos conocimientos con otros frente a lo que se asume una posición crítica pues se reconoce que son saberes que se nos han impuesto desde una cultura dominante, al respecto uno de los estudiantes afirma "en lo que se refiere a los usos y costumbres de la matemática, nos hemos dado cuenta que debemos tener en cuenta el modo de pensar de estas culturas, es como respetar lo que ellos 
piensan y asociarlo a la cultura occidental que es a lo que nosotros estamos acostumbrados y lo que nos han impuesto se podría decir" (Estudiante 3, 2012).

Con respecto a las problemáticas que los estudiantes identifican en el abordaje de la diversidad cultural en el aula, se encuentran la falta de tiempo para el desarrollo de contenidos y el cumplimiento a los estándares impuestos desde el Ministerio de Educación Nacional, y ante el hecho de trabajar con una comunidad culturalmente diversa a la suya identifican como posibles dificultades desconocer la lengua de la comunidad -específicamente si se trata de una comunidad indígena-, la adaptación al contexto y la adaptación a concepciones del conocimiento distintas a la dominante, tal como lo plantea uno de los estudiantes "como problemática veo de pronto el adaptarse un poco a otra concepción de las matemáticas que tenga la comunidad y que no sea como mi concepción" (Estudiante 3, 2012).

Al respecto cabe destacar que los estudiantes reconocen que ante la presión del tiempo, de los estándares y contenidos lineales y rígidos, se terminaría imponiendo lo que pide el sistema, con lo que se devela una contradicción entre lo que consideran lo más adecuado y lo que en realidad harían, ya que a pesar de que reconocen la importancia de conocer el contexto y acercarse a la cultura de los estudiantes y sus formas particulares de construcción de conocimiento, todos coinciden en que la falta de tiempo sería el principal impedimento para hacerlo.

Cabe resaltar que para los estudiantes el reto de la diversidad cultural se relaciona con la distancia o cercanía del contexto educativo con la cultura del docente, es decir, si el docente que llega es el extraño en esa cultura, más grande va a ser el interés y el reto de abordar la diversidad cultural y se buscaría generar estrategias para acercarse y adaptarse al contexto y a la cultura, sin embargo, si llega a un contexto donde confluyen diversas cultu- ras los estudiantes reconocen que sería más fácil adaptarse pues terminarían imponiendo los conocimientos de la cultura dominante a la que pertenecen.

Finalmente, los estudiantes de Licenciatura en Matemáticas, consideran que en el Sistema Educativo Colombiano no se le da importancia al abordaje de la diversidad cultural y que este termina dependiendo de la voluntad de cada docente, al respecto uno de los estudiantes afirma "actualmente creo que no se le da mayor importancia a aquello de la diversidad cultural, se trata de enseñar ciertos contenidos pero no se especifica cómo lo que se debe hacer, no se tiene en cuenta diría nada hasta ahora" (Estudiante 3, 2012). Igualmente se reconoce que por lo general el abordaje de la diversidad cultural es un papel que se ha dejado a entidades no gubernamentales, desconociendo las implicaciones que esto tiene para los contextos educativos.

\section{La mirada de los docentes}

Los docentes y directivos interpretan como positivo el abordaje de la diversidad cultural al permitir el reconocimiento de unos saberes no explorados en la Escuela "tenemos unos saberes ancestrales que nunca antes habían sido reconocidos en la Escuela" (Docente 1, 2012), que además van a posibilitar el desarrollo de nuevas metodologías para enriquecer el proceso de enseñanza - aprendizaje. Asimismo se plantea la necesidad de evitar juzgar los conocimientos de otras culturas, al respecto se afirma "eso es lo que estamos intentando hacer nosotros en relación a la diversidad cultural y con respecto a eso lo que intentamos promover en los estudiantes es el respeto a esa diversidad cultural, evitando juzgar los conocimientos de otras culturas" (Docente 2, 2012), se observa un posición desde una perspectiva multicultural enfocada al respeto por la diversidad cultural y a no juzgar sus saberes, esto a su vez demuestra apertura hacia el tema y disposición para incluirlo como parte del proceso de formación de los futuros docentes. 
Para los docentes al abordar un área de conocimiento como la Etnomatemática -la cual se desarrolla dentro de las materias de Educación y Cultura I y II- se hace un reconocimiento de la diversidad cultural, al comprender que hay procesos matemáticos distintos, necesidades, problemáticas o formas de aprender distintas, lo que implica entender las matemáticas como una construcción y producción social, es decir, como un elemento de construcción humana. De igual manera, el acercarse a contextos culturalmente diversos posibilita conocer lógicas distintas, lo cual es de gran importancia ya que va a permitir no chocarse con otros saberes y no llegar a imponer conocimientos.

Como problemática en el abordaje de la diversidad cultural en la enseñanza de las matemáticas, se identifica el desconocimiento de las diferentes culturas de parte de los futuros docentes, aspecto que se reflejaría cuando se vea enfrentado a una comunidad culturalmente diversa, al respecto se afirma "los problemas no se presentan cuando se trabaja en Pasto donde se impone la lógica dominante, sino cuando el docente se encuentra con lógicas distintas, con formas de concebir la realidad y de construir conocimiento diversas" (Docente 1, 2012), esto iría en concordancia con lo planteado por Magendzo $(2006,11)$, quien llama la atención sobre las implicaciones sociales y políticas de la diversidad cultural en América Latina, para él se debe tener en cuenta que "la diversidad de grupos culturales y sociales distintos, con tiempos discontinuos pero que están simultáneamente presentes, la existencia de una cultura integrada por diversas tradiciones, es y ha sido una característica del mundo latinoamericano... En nombre del orden, de la unidad nacional, de los afanes "modernizantes" y "civilizadores", no sólo se ha negado y rechazado la diversidad sino que se la ha combatido y censurado".

Así mismo, en coherencia con lo planteado por los estudiantes, se percibe que el Sistema Educativo Colombiano, plantea contradicciones con respecto al abordaje de la diversidad cultural, por un lado se exige que los contextos educativos incluyan el tema dentro de sus prácticas de formación pero a la vez los aspectos que se evalúan no tienen en cuenta estos elementos, sino que se relacionan con un sistema homogeneizante que exige enseñar a todos lo mismo y evaluar con los mismos criterios

Desde una lógica de la diversidad uno diría tendrá que debe haber una forma de evaluarlos distinta pero no la hay. De la forma en que se evalúa en la zona urbana así mismo se evalúa a una comunidad indígena en el Amazonas, exactamente igual. Entonces uno dice esto es un engaño, una contradicción, porque nos dicen que hagamos una cosa $y$ nos evalúan con otra. Entonces uno dice bueno y ahora qué hacemos? (Docente 1, 2012).

En este punto resulta central el planteamiento que realizan Batallán y Campanini $(2008,171)$ en relación a la contradicción que representa el hecho de que a la escuela se le exige "difundir y sostener una norma universalmente válida para todos y al mismo tiempo realizar su obligación contemporánea, de respetar y -hacer respetar- la diferencia de los niños que son supuestamente portadores de una cultura particular", planteamiento a partir del cual se advierte la relación no sólo entre los conceptos de diferencia, diversidad y cultura sino y sobre todo la relación contradictoria que se presenta entre las teorías y las normas que abordan la diversidad y la diferencia y las prácticas en el contexto educativo.

Condiciones necesarias para la emergencia y movilización de sentidos de diversidad cultural

A nivel institucional la Universidad de Nariño cuenta con un PEI y un PDI que reconocen la importancia que tienen en el quehacer universitario temas relacionados con la diversidad cultural, la multi 
e interculturalidad pero se reconoce que para su pleno abordaje se hace necesaria la flexibilización del curriculum, la transversalización de lo propio al curriculum, y la implementación de herramientas curriculares integrales, de acuerdo a lo planteado en el PDI (2008), se hacen necesarias formas pedagógico-curriculares que permitan la interdisciplinariedad y la transdisciplinariedad y según lo planteado en el PEP (2010) se requiere propiciar el diálogo de saberes basado en una perspectiva Sociocultural e Interdisciplinaria.

Desde la percepción de los estudiantes, el Programa de Matemáticas brinda espacios académicos formales y continuos en los que se abordan temas relacionados con la diversidad cultural, entre los que se destaca las materias de Educación y Cultura I y II que les proporcionan las principales herramientas teóricas frente a la diversidad cultural y les han permitido "generar conciencia frente a la importancia de considerar los aspectos culturales dentro de los procesos de enseñanza aprendizaje" (Estudiante 5, 2012), lo que puede sintetizarse en una disposición o actitud favorable para abordar los procesos educativos desde esta perspectiva, actitud que de acuerdo con los estudiantes implica "no imponer conocimientos y aprender a identificar problemas en el proceso de enseñanza - aprendizaje teniendo en cuenta la diversidad cultural de los estudiantes" (Estudiante 4, 2012). Asimismo se destaca la necesidad manifestada por los estudiantes, de establecer espacios de encuentro y reflexión acerca de la diversidad cultural y la educación con las diferentes comunidades que hacen parte del contexto universitario.

Por su parte los docentes en coherencia con lo planteado por los estudiantes y lo evidenciado en el PEP, consideran que el principal espacio que se ha generado en el programa en relación a la diversidad cultural es la inclusión formal del área de Etnomatemáticas dentro del Plan de estudios, la cual incluye el desarrollo de prácticas a comunidades indígenas del
Putumayo y comunidades afrocolombianas de la Costa Pacífica Nariñense, con el propósito de facilitar el contacto con comunidades culturalmente diversas para los estudiantes, lo que claramente hace evidente el énfasis étnico-racial que prevalece en el abordaje de la diversidad cultural, sin desconocer con ello el trabajo que se viene adelantando desde este programa al vincular directamente la diversidad cultural como parte de la formación de los futuros docentes.

\section{En conclusión ¿Cuáles son los sentidos de la diversidad cultural y sus diálogos imperfectos?}

\section{Énfasis en la dimensión étnico racial de la diversidad cultural}

Si bien al hablar de diversidad cultural aparecen algunas posturas, desde la institución, estudiantes y docentes, que indagan por las diferencias de género, de clase, de edad, y población de frontera, tanto en los elementos conceptuales como en las actividades y estrategias propuestas para abordar la diversidad cultural, se evidencia una tendencia a relacionar esta categoría con lo étnico racial, especialmente en relación a las comunidades indígenas y afrocolombianas que permanecen circunscritas en su territorio, con lo que se conserva una postura esencialista de la cultura, desde la que se pierden de vista las diferentes manifestaciones de diversidad cultural que pueden presentarse en el aula sin que ésta deba hacer parte de las comunidades mencionadas ni ubicarse en un contexto apartado. Desde este sentido se puede considerar entonces que la diversidad del Otro sólo es relevante cuando está aislado, apartado y que su diversidad deberá desconocerse, asimilarse o segregarse cuando existe una mayoría que lo desconoce e invisibiliza. 


\section{La diversidad cultural como déficit o limitación}

Tanto en el sentir de los estudiantes y docentes como en los documentos analizados, se hace evidente un énfasis de la diversidad cultural desde el déficit y se la concibe como una limitación que debe ser superada garantizando a los estudiantes alcanzar condiciones de igualdad, este aspecto resulta inquietante puesto que de la mirada que se tenga de la diversidad cultural va a depender su posterior abordaje, pues al concebirla como un déficit únicamente se va a buscar que éste sea superado, mientras que si se la ve como potencialidad se va a reconocer su valor como posibilidad para enriquecer el proceso de formación.

\section{La postura multicultural del respeto a la diferencia}

A nivel institucional y como parte del discurso de estudiantes y docentes, se hace un especial énfasis sobre el respeto, la tolerancia y el reconocimiento de la diferencia, visto más como un principio moral o axiológico pero sin proponer un cuestionamiento claro frente a las posiciones de inequidad y desigualdad que genera el desconocimiento de los múltiples saberes propios de una sociedad multicultural a la que tanto se hace referencia, es decir, aunque se plantea la necesidad de un diálogo de saberes no se cuestionan los lugares de poder desde donde se construye el conocimiento y el papel de la universidad en la construcción del mismo, ni se analizan las condiciones para que este diálogo sea posible en condiciones de horizontalidad, de manera que el Otro sea genuinamente escuchado y no termine siendo utilizado para la imposición de un pensamiento hegemónico, esto no desconoce que la Universidad viene construyendo un discurso en torno a la diversidad cultural y que existen dificultades al introducir estas nuevas miradas y formas de construir y concebir el conocimiento en instituciones permeadas por lógicas dominantes, tradicionales y hegemónicas.

\section{La Unidad Nacional vs la Diversidad Cultural}

Las posturas estatales que buscan por un lado el mantenimiento de la unidad nacional y por el otro el reconocimiento de la multiculturalidad, reflejan incoherencias de fondo que cuestionan el verdadero sentido e interés que tiene la diversidad cultural para el sistema educativo, incoherencias que son fácilmente identificadas por docentes y estudiantes especialmente en lo que se refiere a la homogeneización de tiempos y estándares caracterizados por contenidos que difunden una perspectiva occidental, científica y moderna del conocimiento y las evaluaciones que niegan cualquier posibilidad de diferencia y chocan con cualquier actitud o disposición favorable que al respecto se esté gestando en los futuros docentes, quienes admiten que bajo estas condiciones terminarán cediendo a las presiones del sistema e imponiendo sus posiciones o conocimientos, lo que evidencia que el sistema educativo fracasa en la apuesta por la diversidad cultural nada más en la evaluación, entrampándose en la forma como imparte y valora los conocimientos desde la academia.

\section{Contradicciones con las demandas del Estado}

Existen contradicciones entre lo que la Universidad de Nariño plantea desde su visión, misión y principios y lo que el Sistema Educativo Nacional exige, por un lado la universidad muestra apertura para el abordaje de la diversidad cultural, el reconocimiento del pensamiento propio y la construcción de modelos alternativos desde lo local, como posibilitadores de formas alternativas de desarrollo que contribuyan al buen vivir de las comunidades, mientras que desde el sistema educativo prima el cumplimiento de estándares que obligan a que la institución mantenga dinámicas y modelos tradicionales en las formas de 
construir y reproducir el conocimiento, desde los cuales van a ser evaluados tanto las instituciones como los futuros profesionales, ejerciéndose una presión difícil de resistir tan sólo desde la buena voluntad de las instituciones y los docentes, lo que indica que se requiere una transformación estructural frente al verdadero papel que debe tener la diversidad cultural en los contextos educativos.

\section{¿Diversidad como metodología/ estrategia de unidad e imposición?}

El tener en cuenta la diversidad cultural dentro de los procesos de enseñanza aprendizaje sin garantizar las condiciones para un diálogo horizontal de saberes que posibilite la construcción conjunta de conocimiento, puede constituirse también en una nueva estrategia de imposición de conocimientos occidentales, es decir en una forma más sutil en la que se reconozca la diferencia, no para aprender de ella sino para educar/instruir más fácilmente a través de ella, a manera de metáfora no garantizar estas condiciones nos podría ubicar ante una nueva versión de evangelización pero esta vez no de una religión, sino de una postura moderna, científica y occidental del conocimiento.

\section{Cuando el extraño es uno}

El presente estudio hizo evidente que la posición frente a la diversidad cultural y las actitudes frente a la misma en el quehacer pedagógico varían dependiendo de dos circunstancias, una cuando en el contexto educativo el docente hace parte de la supuesta cultura mayoritaria, homogénea y dominante, situación en la que se admite que no se le otorgaría suficiente relevancia a la categoría de diversidad cultural bajo argumentos como la falta de tiempo o los estándares de evaluación, y se reconoce que se terminaría por imponer una forma de conocimiento y una metodología. Sin embargo, cuando es el docente el diverso en un contexto educativo, por ejemplo cuando debe desempeñar su rol en una comunidad indígena o afrocolombiana a la que no pertenece, entonces el interés por la cultura de la comunidad aumenta así como el interés por adecuar las metodologías a las necesidades de los estudiantes, desde este sentido la diversidad cultural tiene importancia en la medida en que el docente se siente extraño o diferente en relación a la comunidad educativa pero se invisibiliza cuando confluyen múltiples culturas en el aula.

\section{Del dicho al hecho...}

Para terminar, si bien se encuentran elementos importantes que evidencian que a nivel curricular se están desarrollando procesos para acercar a los futuros docentes al tema de la diversidad cultural, lo cual se evidencia en su actitud de interés y disposición para considerar los aspectos culturales de los estudiantes dentro del proceso de enseñanza aprendizaje, también se reconocen fuertes impedimentos del sistema educativo colombiano, que antes de iniciar su ejercicio docente, hace pensar a los estudiantes que se trata de una tarea difícil de lograr si el sistema mantiene su énfasis homogeneizador y continúa desconociendo en la práctica la diversidad cultural de nuestro país.

\section{A manera de recomendaciones}

- La experiencia del programa de Licenciatura en Matemáticas hace evidente que en cualquier área de conocimiento es factible y sobre todo necesario incluir el tema de la diversidad cultural como parte del proceso de formación de los futuros docentes, de manera que se posibiliten condiciones genuinas para la pretendida construcción de pensamiento colectivo y complejo tan en boga en los planes de desarrollo y proyectos educativos de las instituciones de educación superior.

- Se hace necesario reflexionar de manera más profunda sobre las implicaciones de conceptos como multiculturalidad e interculturalidad en la educación superior, pues aunque tienden a usarse indiscriminadamente 
difieren en los cuestionamientos que realizan sobre las situaciones de inequidad, desigualdad y posiciones de poder desde las cuales se construye el conocimiento y se reconoce la diversidad y la diferencia.

- La diversidad cultural que hace parte de la mayoría de las instituciones educativas colombianas puede constituirse en un espacio idóneo para dialogar y reflexionar frente al papel de los docentes y la educación en torno a la diversidad cultural, lo que implica empezar la tarea de mirar desde adentro, cuestionando la manera como se está abordando la diversidad cultural en este nivel para generar transformaciones en las prácticas que se desarrollan en los demás niveles de educación.

- Los procesos de formación de los futuros licenciados frente al tema de la diversidad cultural, deben superar concepciones esencialistas y étnico raciales que invisibilizan la presencia de otras diversidades culturales en el aula, desconociendo los complejos procesos sociales de un país como Colombia cuya constante movilidad social requiere que seamos capaces no sólo de ser buenos ciudadanos sino de relacionarnos adecuadamente con la diversidad y la diferencia.

- El reconocimiento social que tiene la universidad en la sociedad debe ser aprovechado para cuestionar la estructura actual del sistema educativo en torno al abordaje de la diversidad cultural, pues si no se producen transformaciones estructurales, el discurso de la diversidad cultural no dejará de ser uno más de los frecuentes temas de moda que generalmente se insertan en el sistema educativo.

\section{Referencias}

Albán, Adolfo. (2008). ¿Interculturalidad sin decolonialidad? colonialidades circulantes y prácticas de re-existencia. Diversidad, Interculturalidad y construcción de ciudad. Bogota: D'vinni S.A

Alonso, María José; Navarro, Raquel y Vicente, Lidón. (S,f). Actitudes hacia la diversidad en estudiantes universitarios. En: http://www. uji.es/bin/publ/edicions/ffi13/44.pdf. (Recuperado en Julio 24 del 2012).

Asamblea Nacional Constituyente (1991) Constitución política de Colombia de 1991.

Batallán, Graciela y Campanini, Silvana. (2008). El respeto a la diversidad en la escuela: atolladeros del relativismo cultural como principio moral. En: http://revistas.ucm.es/index.php/ RASO/article/view/RASO0707110159A/9142 (Recuperado en Diciembre 13 del 2011).

Cárdenas, Claudia. (2011). La diversidad en la diversidad. Módulo Educación para la Diversidad. Universidad de Manizales. Manizales: CEDUM.

Castro, Celmira. (2009) Estudios sobre educación intercultural en Colombia: tendencias y perspectivas En: Memorias. Revista Digital de Historia y Arqueología desde el Caribe, Vol. 6, Núm. 10, julio, 2009, pp. 358-375 Universidad del Norte Colombia.

Del Arco, Isabel. (1999). Curriculum y Educación Intercultural: Elaboración y aplicación de un programa de Educación Intercultural. Tesis Doctoral. En: http:// www.tdx.cat/bitstream/handle/10803/8303/ Tidb2de10.pdf;jsessionid= CCB1BD01E01521C0FE783549F5631418. $\mathrm{td} \times 2$ ? sequence $=3$ (Recuperado 25 Julio 2012).

Freire, Paulo. (1992). Pedagogía de la esperanza. Rio de Janeiro: Siglo Veintiuno Editores.

Geertz, Clifford. (2005). El impacto del concepto de cultura en el concepto de hombre. La interpretación de las culturas.Barcelona: Gedisa,S.A.

Gil Juarena, Inés. (2007). Percepciones de la diversidad y los logros escolares. Análisis desde un enfoque intercultural. En: http://www. uned.es/grupointer/Emigra\%20Working\% 20Papers\%20,\%2087_\%20Gil\%20Jaurena. pdf (Recuperado en Julio 24 del 2012). 
Ghiso, Alfredo (2000). Potenciando la diversidad (Diálogo de saberes, una práctica hermenéutica colectiva). En: http://bibliotecadigital.conevyt.org. $\mathrm{mx} /$ colecciones/ documentos/potenciando_diversidad.pdf (Recuperado Junio 13 de 2012).

González González, Miguel Alberto. (2011). Extrañamiento del otro. Manizales: Universidad de Manizales.

González González, Miguel Alberto. (2012). Falacias de la igualdad y precariedades de la libertad. Manizales: Universidad de Manizales.

Hernández De La Torre, Elena. (2010). La diversidad social y cultural como fuente de enriquecimiento y desarrollo: aspectos conceptuales. En: http://www.redes-cepalcala. org/inspector/DOCUMENTOS $\% 20$ Y $\% 20$ LIBROS/EDUCACION-ESPECIAL/LA $\% 20$ DIVERSIDAD\%20COMO\%20FUENTE\%20 DE\%20ENRIQUECIMIENTO.pdf. (Recuperado en Abril 20 de 2012).

Hernández, Gregorio. (2011). Paradigmas que fundamentan el concepto de cultura. Modulo concepto de cultura. Maestría en Educación desde la diversidad. Universidad de Manizales.

Llanquinao, Hilda. (2009), Los valores de la educación tradicional mapuche, posibles contribuciones al sistema educativo chileno. En: http://www.tesisenred.net/bitstream/handle/10803/2356/HLLT_TESIS. pdf? sequence=1 (Recuperado en Julio 13 del 2012).

Magendzo, Abraham. (2006). El Ser del Otro: un sustento ético-político para la educación. Red de Revistas Científicas de América Latina, el Caribe, España y Portugal. Disponible en: http://redalyc.uaemex.mx/src/ inicio/ArtPdfRed.jsp?iCve=30517306007 (Recuperado en Abril 15 de 2012).

Ministerio de Educación Nacional. (2006). Plan Decenal de Educación 2006-2016. En: http://www.plandecenal.edu.co/html/1726/ w3-article-166057.html (Recuperado Julio 30 de 2012).

Ministerio de Educación Nacional (2005). Lineamientos de política para la atención educativa a las poblaciones vulnerables. Bogotá, Colombia. En: http://www.mineducacion.gov.co/cvn/1665/articles-90668_archivo_pdf.pdf. (Consultado el 15 de Mayo de 2012).
Ministerio de Educación Nacional (1994). Ley 115 de 1994. Disponible en: http://www.mineducacion.gov.co/1621/articles-85906_archivo_pdf.pdf (Consultada Mayo 15 de 2012)

Ministerio de Educación Nacional (1992). Ley 30 de 1992. En: http://www.mineducacion. gov.co/1621/articles-86437_Archivo_pdf.pdf (Consultada el 15 de Mayo de 2012).

Ojeda, Elizabeth; González, Patricia; Martínez, María Fernanda; Rodríguez, Diana; Caicedo, Ana; Pantoja, Mauricio y Zambrano; Christian. (2012). Prejuicios y estereotipos entre estudiantes universitarios Pertenecientes y No Pertenecientes a Comunidades Indígenas, Afrocolombianas y Homosexuales de la Universidad de Nariño. Investigación presentada en el Concurso de Investigación Docente Alberto Quijano Guerrero de la Universidad de Nariño.

Osorio, Karla. (2007). Atención a las Necesidades Especiales desde el Sistema Educativo Regular: La Experiencia de una comunidad educativa que convive y aprende con la Diversidad. En: http://www. cervantesvirtual.com/obra/atencion-a-lasnecesidades-especiales-desde-el-sistema educativo-regular-la-experiencia-de-unacomunidad-educativa-que-convive-y-aprende-en-la-diversidad/ (Recuperado en Julio 25 del 2012).

Rodríguez, Rosa. (2008) Atención educativa a la diversidad étnico-cultural: nuevas competencias profesionales del profesorado. En: http://redalyc.uaemex.mx/src/inicio/ArtPdfRed.jsp?iCve $=56712875014$. (Recuperado en Julio 1 del 2012).

Rodríguez, Rosa. (2005). Estudio de las concepciones de los estudiantes de Magisterio sobre la Diversidad Cultural. En: http://www. raco.cat/index.php/educar/article/viewFile/39742/39580. (Recuperado en Julio 24 del 2012).

Rodríguez, Mónica. (S, f). Diversidad cultural y educación intercultural. Universidad de Vigo. En: http://www.educacion.udc.es/ grupos/gipdae/congreso/VIIIcongreso/ pdfs/174.pdf (Recuperado el 23 de Julio de 2012).

Rojas, Axel. (S,f). Inclusión social, interculturalidad y educación. ¿Una relación (im) posible?. En: www.foro-latino.org/flape/ foros_virtuales/.../FV4-Presentacion.pdf (Consultado el 1 de Noviembre de 2011). 
UNESCO (2001) Declaración Universal de la UNESCO sobre la Diversidad Cultural: una visión, una plataforma conceptual, un semillero de ideas, un paradigma nuevo. Johannesburgo: 26 de agosto - 4 de setiembre 2002. En: http://unesdoc.unesco. org/images/0012/001271/127162s.pdf (Recuperado en Mayo 6 del 2012).

Universidad de Nariño. (2010). Proyecto Educativo Pedagógico del Programa de Licenciatura en Matemáticas.

Universidad de Nariño. (2009). Proyecto Educativo Institucional. Disponible en: http://akane. udenar.edu.co/siweb/secretaria_1/archivos/ Proyecto-educativo-institucionā-2009.pdf (Recuperado en Julio 30 del 2012)

Universidad de Nariño. (2006). Plan Marco de Desarrollo Institucional 2008 - 2020. En: http://reforma.udenar.edu.co/wp-content/
uploads/2010/03/PLAN DE DESARROLLO_UDENAR_2008_2020.p̄df (Recuperado en Julio $30 \overline{\text { de }} 20 \overline{12}$ ).

Villa, Wilmer y Grueso, Arturo (2008). Emergencias posibles desde la construcción de la interculturalidad. Diversidad, Interculturalidad y construcción de ciudad. Bogota: D'vinni S.A.

Walsh, Catherine. (2008). Interculturalidad crítica Pedagogía de-colonial. Diversidad, Interculturalidad y Construcción de Ciudad. Bogotá: D'vinni S.A.

Zino, Julio. (2000). Algunos conceptos básicos: La estructura social, Murcia, Universidad Católica San Antonio. En: file:///C:/Users/familia\%20martinez/ Downloads/Algunos $\% 20$ conceptos $\% 20$ b\%C3\%A1sicos\%20(1).htm. (Recuperado en Julio 27 de 2012). 